\title{
Survival Analysis of Duration of exclusive breastfeeding in Ethiopia: Comparison of Proportional Hazard model and Accelerated Failure Time models
}

Bacha Ewunetu Gemechu ( $\square$ bacha.ewonetu@amu.edu.et )

Arba Minch University

Tilahun Bedaso Merga

Arba Minch University

\section{Research}

Keywords: Exclusive breastfeeding, Cox proportional hazards model, AFT model, duration of EBF

Posted Date: October 5th, 2021

DOl: https://doi.org/10.21203/rs.3.rs-934202/v1

License: (a) (1) This work is licensed under a Creative Commons Attribution 4.0 International License.

Read Full License 


\title{
Survival Analysis of Duration of exclusive breastfeeding in Ethiopia: Comparison of Proportional Hazard model and Accelerated Failure Time models
}

\author{
Bacha Ewunetu Gemechu, Department of Statistics, Arba Minch University \\ Email : bacha.ewunetu@yahoo.com \\ Tilahun Bedaso Merga, Department of Statistics, Arba Minch University \\ Email : tilahun.bedaso@gmail.com
}

\begin{abstract}
Introduction

Early cessation of EBF has the short and long term effect for the welfare of infants including the life-long impacts of poor school performance, reduced productivity, and impaired intellectual development. Objective of the study: the main objective of this study was to compare the performance of CPH model and AFT models in analyzing EBF data in Ethiopia, 2016 EDHS. Specifically, the study aimed to identify the major predictor variables of the duration of EBF based on 2016 EDHS data.
\end{abstract}

Methodology: The secondary data is obtained from Ethiopian Demographic and Health Survey (EDHS), 2016. The outcome variable of this study was the duration of EBF in month. To achieve the objective of the study, descriptive survival analysis like the median survival time, Kaplan Meier survival estimate and log-rank test were used to compare the estimated survival probability among different levels of predictor variables at 5 percent significant level. The Cox proportional hazard regression and Accelerated failure time model were fitted and their results were compared using model comparison criterion such as AIC, BIC.

Results: of 1092 interviewed mothers, $15.3 \%$ of them were discontinued EBF and $84.7 \%$ of them were exclusively breastfed (censored). The estimated median duration of EBF was 3 months. Based on estimated Kaplan Meier survival curve and log-rank test, it was found that there was a statistically significant difference in survivor experience of discontinuing EBF over 
each duration with respect to place of delivery, maternal education, husband education, mode of delivery and employment status. The fitted CPH and AFT model indicated that mode of delivery, wealth index, and employment status was found as significant predictors of EBF duration. Moreover, comparatively Weibull AFT model performed better in analyzing EBF data. According to the fitted model, mothers who were in poor wealth index category and who gave birth by cesarean shortens the duration of EBF by $16 \%$ and $29 \%$ respectively. On the other hand, employed mothers were improved the duration of EBF by $26 \%$.

Conclusion: Weibull AFT model is performed better in analyzing EBF data. A mother who was unemployed, poor wealth index, and gave birth by cesarean shortens the duration of EBF than their counterparts. Therefore, special emphasis should be given for mothers who are unemployed, who are economically poor, and give birth by cesarean to improve the duration of EBF.

Keywords: Exclusive breastfeeding, Cox proportional hazards model, AFT model, duration of EBF.

\section{INTRODUCTION}

Exclusive breastfeeding is the practice of feeding only breast milk (including expressed breast milk) and allows the baby to receive vitamins, minerals or medicines and water, breast milk substitutes, other liquids and solid foods are excluded [1]. Fatty acids needed for the infant's growing brain, eyes, and blood vessels are the only contents of breast milk that are not available in other types of milk. Moreover, breast milk helps against multiple diseases, such as gastrointestinal and acute respiratory infections [2], thus, reduces infant mortality and helps faster recovery during illness. In recognition of these benefits, WHO and the United Nations Children's' Fund (UNICEF) recommends all mothers should breastfeed exclusively for the first six months of life and continued breastfeeding for two years or more in conjunction with complementary food as human milk alone is no longer sufficient for both nutritional and developmental reasons [3].

Globally approximately $40 \%$ of infants and in developing countries $38 \%$ of infants were exclusively breastfed respectively $[2,5]$. Among $96 \%$ of all infants' death occur in the world each year non-exclusive breastfeeding share $55 \%$ of diarrheal death and $53 \%$ of acute respiratory 
deaths which is much higher in Asia and Africa [6, 25]. On the other hand, exclusive breastfeeding practice is the most effective intervention to save the lives of infants and children. Nearly, $13 \%-15 \%$ of deaths of children aged less than five years could be prevented if universal coverage of EBF were increased to $90 \%$ among infants aged less than six months [4]

Even though the Ethiopian Health Sector Transformation Plan (HSTP IV) had planned to increase the proportion of exclusive breastfeeding from $52 \%$ to $72 \%$ by the end of 2020 , only $58 \%$ of infants exclusively breastfed with a median duration of 3.1 months (EDHS, 2016) and other available studies in different parts of Ethiopia indicated that the prevalence is ranges from $40.6 \%$ to $81.1 \%[\mathbf{1}, \mathbf{2}, \mathbf{3}, \mathbf{6}, \mathbf{7}, \mathbf{1 0 - 1 8}, \mathbf{2 2}, \mathbf{2 4}, \mathbf{2 5}, \mathbf{2 7}]$.

Age at Early cessation of EBF before six months in developing countries like Ethiopia leads to risk of pathogens contamination and over dilution of milk leading to increased risks of morbidity , under nutrition and mortality, by reducing the ingestion of protective factors present in breast milk and increasing the exposure to sources of contamination [4]. However, several studies show the age at termination of EBF is less than that of WHO recommendation. For instance, the median duration of EBF in India, south Gujarat region of India, and Indonesia was 4.2,6 and 2.03 respectively [7, 8, 9]. Moreover, the median duration of EBF in Brazil, Congo Kinshasa, China, was 3 months, 10.9 weeks, 4.5 months respectively [28,29,31]. In Ethiopian context, few studies reported that the duration of EBF ranges from 1 month in Addis Ababa to 4.77 months in Afar region of Ethiopia $[8,10,11,18,23,24]$.

Since the age at Early cessation of EBF has the short and long term effect for the welfare of infants including the life-long impacts of poor school performance, reduced productivity, and impaired intellectual development it is very important variable to determine the important factors of EBF duration. Survival analysis is used for this purpose, statistical methods frequently used to analyze time to event data and has an advantage of controlling censoring observation than any other statistical methods. Cox Proportional Hazard model is the popular model in analyzing survival data, which assume constant hazards. However, the assumption of constant hazards in PH model is not always satisfied by the survival data. The misinterpretation of parameter estimation and decreasing the power of statistical tests are associated with violation of the $\mathrm{PH}$ assumptions. On the other hand, Accelerated Failure Time models can be used as the alternative to Cox PH model if the constant hazards' assumption is violated, that is why we want to compare 
the $\mathrm{CPH}$ and AFT models for the analysis of current EBF data. To the best our knowledge, no study had been conducted to determine the determinants of EBF duration by comparing CPH regression and AFT model. Therefore, the main objective of this study was to compare the performance of CPH model and AFT models in analyzing EBF data in Ethiopia, 2016 EDHS. Moreover, the major factors of early cessation of EBF would be identified.

\section{METHODOLOGY}

\subsection{Data Source}

The secondary data was obtained from Ethiopian Demographic and Health Survey (EDHS) 2016. The survey is conducted from January 18, 2016-June 27, 2016 jointly by the Central Statistical Agency (CSA), Ministry of Health $(\mathrm{MoH})$, the Ethiopian Public Health Institute and the United States Agency for International Development (USAID) funded the survey (EDHS, 2016).

\subsection{Study Design and Source population}

The 2007 Ethiopia population and Housing Census (PHS) is used as a sampling frame of 2016 EDHS and in the first stage 202 in urban areas and 443 rural areas within the nine regions and two administrative cities and thereafter as a second stage, 28 households per cluster were selected with equal probability. Finally the sample used for this study is taken from women's data and total number of children included was 1092. Sampling unit of this study was women whose last child is younger than six months and living with their mothers only.

\subsection{Study Variables}

The duration of EBF was the outcome variable (survival time) and breastfeeding status was an event indicator dichotomized as 1 , if a child is given any type of food or liquid other than breast milk before six months and 0, otherwise. The main independent variables taken from available studies related to duration of EBF and its determinants [8, 26-34] are husband educational level, wealth index of household, place of residence, mother educational level, employment status, age at first birth, age of mothers during the last birth, place and mode of delivery, birth order, previous birth interval, sex of a child, infant antenatal check-up (ANC).

\subsection{Method of Data Analysis}

\subsubsection{Descriptive Survival analysis}


Kaplan Meier survival estimators, median survival time, log-rank test, were used for analysis of survival data. Kaplan Meier survival estimator is used to compare survivor experience of event among different level of predictor variables and log-rank test is used to evaluate whether there is statistically a significant difference among KM survival curves. At null hypothesis log-rank statistic is approximately distributed as chi-square distribution with k-1 degree of freedom, and we conclude that there is a significant difference among KM survival curves if p-value is less than 5 percent significance level. All data analysis was performed using stata version14.2.

\subsubsection{The Cox proportional hazard (CPH) regression model}

$\mathrm{CPH}$ regression model is a semi-parametric survival model and used to identify the effect of several factors on the duration of EBF. The Cox proportional hazard model is expressed as $h(t \mid X)=h_{0}(t) \exp ^{X^{T} \beta}$, where $X=\left(X_{1}, X_{2}, \ldots, X_{p}\right)^{T}, X$ is a $p \times 1$ vector covariate and $\beta$ is a $p \times$ 1 vector of regression coefficients. The parameters were estimated by partial likelihood functions and significance of the coefficients was tested using the partial likelihood ratio test, Wald test, and score test. We used Hosmer and Lemeshow and Collet recommendations for a variable selection: including all variables that are significant in the uni-variable analysis at the 20 to 25 percent level and multivariable analysis at 5 percent level.

\subsubsection{Overall goodness of fit}

Testing proportional hazards assumption: this can be assessed by log-log plot and schoenfel residual. If the plot of $\log (-\log (S(t)))$ versus $\log (S(t))$ for each covariate shows non-parallel curve, the ph assumption won't met. On the other hand, the ph assumptions are also examined by evaluating whether there is a correlation between schoenfeld residual and survival time. A correlation of zero indicates that the model met the proportional assumptions. In addition, CoxSnell residual is used to assess the overall model fit. If the model fits the data, the plot of the cumulative hazard versus Cox Snell should approximate straight line with slope 1.

Model comparison: Akaike information criteria (AIC) and Bayesian information criteria (BIC) are used to compare CPH model and AFT model, and they are given by, AIC $=-2(\log -$ likelihood $)+2(p+k), B I C=-2(\log -$ likelihood $)+(p+k) * \log (n)$ where $\mathrm{p}$ is number of parameter and $\mathrm{k}$ is a number of coefficients (excluding constant) in the model.

\section{Accelerated failure time model}


AFT model provides an alternative to $\mathrm{CPH}$ model for statistical modeling of survival data when the proportional hazard assumption of Cox model is do not satisfied (Wei, 1992). In this model, the logarithm of survival time is response variable and includes an error term which is assumed to follow specific probability distribution such as exponential, Weibull, log-normal, log-logistic, etc. The assumption of AFT model is that the effects of covariates act multiplicatively with respect to survival time. The log linear representation of AFT model is given by

$\log T_{i}=\mu+\beta_{1} x_{1}+\beta_{2} x_{2}+\cdots+\beta_{p} x_{p}+\sigma \varepsilon_{i}$, where $\log T_{i}$ is $\log$ transformed survival time for individual $\mathrm{i}, \mathrm{X}^{\prime}$ and $\beta_{i}{ }^{\prime}$ represents vector covariates and coefficients respectively; $\varepsilon_{i}$ is unexplained variation of $\log$ transformed survival time and $\mu$ and $\sigma$ are intercept and scale parameter respectively. The unknown $\mathrm{p}+2$ parameters of the model are estimated by maximum likelihood estimation.

\section{Results}

\section{Summary of Socio demographic characteristics of Respondents}

Among 1092 interviewed mothers used for this study, $15.3 \%$ of them discontinued EBF and $84.7 \%$ of them were continued EBF (censored).

Almost half $(49.3 \%)$ of the babies were males, of whom those who exclusively breastfed accounts for $47.8 \%$ and $57.8 \%$ of them were didn't exclusively breastfed. In contrast, of 545 female babies $52.2 \%$ were exclusively breastfed and $42.4 \%$ were didn't exclusively breastfed. The percentage of exclusively breastfed babies was higher (46.7\%) for those first born than those born in the $2^{\text {nd }}$ and $3^{\text {rd }}$ and $4^{\text {th }}$ and above. The percentage of EBF was higher $(55.3 \%)$ for those mothers delivered at home than for those mothers delivered at health facility $(44.7 \%)$. Regarding the number of births for each pregnancy, almost all single births (99\%) were exclusively breastfed and only $1 \%$ of multiple births were exclusively breastfed. The percentage of EBF for the employment status was $63 \%$ and $37 \%$ for unemployed and employed mothers respectively. The highest percentage of EBF in Mode of birth variable was observed for women who gave birth vaginally than those who gave birth by Cesarean. Regarding the wealth index of mothers the highest (51.2\%) and lowest percentage of EBF (13\%) was observed for Poor and medium class of mothers respectively. The highest percentage of EBF was observed for those mothers from rural areas $(81 \%)$ than for those mothers from urban areas (19\%). Regarding the proportion of EBF in age group the highest proportion was observed for mothers in the age group <20 years $(57.6 \%)$ followed by those in the age group of 20 to 29 (41.5\%) and 30 and above years $(0.9 \%)$ 
respectively. The percentage of EBF for those mothers attended ANC for fewer than four times (80\%) was observed as four times higher than those attended ANC for at least four times (20\%). Finally, the proportion of EBF for the number of children ever born was higher for mothers who had one to three children $(53.3 \%)$ followed by those who had 4 to $6(31.1 \%)$ and 7 and higher $(15.6 \%)$ respectively (Table1).

Table1. Cross tabulation of Socio-demographic characteristics of mothers who had infant aged below six months by Breastfeeding status, 2016 EDHS data

\begin{tabular}{|c|c|c|c|c|}
\hline \multirow[t]{2}{*}{ Variable } & \multirow[t]{2}{*}{ Category } & \multicolumn{2}{|c|}{ Breastfeeding Status } & \multirow[b]{2}{*}{ Total (percentage) } \\
\hline & & $\mathrm{EBF}$ (percentage) & Non-EBF(percentage) & \\
\hline \multirow[t]{2}{*}{ Sex } & Male & $435(47.8 \%)$ & $95(57.6 \%)$ & $530(49.3 \%)$ \\
\hline & Female & $475(52.2 \%)$ & $70(42.4 \%)$ & $545(50.7 \%)$ \\
\hline \multirow[t]{3}{*}{ Birth order } & First & $196(21.5 \%)$ & \multirow{2}{*}{$\begin{array}{l}35(21.2 \%) \\
41(24.8 \%)\end{array}$} & $231(21.5 \%)$ \\
\hline & $2^{\text {nd }}$ and $3^{\text {rd }}$ & $289(31.8 \%)$ & & $330(30.7 \%)$ \\
\hline & $4^{\text {th }}+$ & $425(46.7 \%)$ & $89(53.9 \%)$ & $514(47.8 \%)$ \\
\hline \multirow[t]{2}{*}{ Place-delivery } & Home & $494(55.3 \%)$ & $118(71.5 \%)$ & $612(57.8 \%)$ \\
\hline & $\begin{array}{l}\text { Health } \\
\text { facility }\end{array}$ & $400(44.7 \%)$ & $47(28.5 \%)$ & $447(42.2 \%)$ \\
\hline \multirow[t]{2}{*}{ Birth type } & Single & $902(99.1 \%)$ & $162(98.2 \%)$ & $1064(99 \%)$ \\
\hline & Multiple & $8(0.9 \%)$ & $3(1.8 \%)$ & $11(1.0 \%)$ \\
\hline \multirow[t]{2}{*}{ Emp_status } & Unemployed & \multirow{2}{*}{$\begin{array}{l}575(63.2 \%) \\
335(36.8 \%)\end{array}$} & \multirow{2}{*}{$\begin{array}{l}131(79.4 \%) \\
34(20.6 \%)\end{array}$} & $706(65.7 \%)$ \\
\hline & Employed & & & $369(34.3 \%)$ \\
\hline \multirow[t]{2}{*}{ Birth method } & \multirow{2}{*}{$\begin{array}{l}\text { Normal } \\
\text { Cesarean }\end{array}$} & \multirow{2}{*}{$\begin{array}{l}883(97.0 \%) \\
27(3.0 \%)\end{array}$} & \multirow{2}{*}{$\begin{array}{l}151(91.5 \%) \\
14(8.5 \%)\end{array}$} & $1034(96.2 \%)$ \\
\hline & & & & $41(3.8 \%)$ \\
\hline \multirow[t]{3}{*}{ Wealth index } & Rich & \multirow{3}{*}{$\begin{array}{l}326(35.8 \%) \\
118(13) \\
466(51.2 \%)\end{array}$} & \multirow{3}{*}{$\begin{array}{l}43(26.1 \%) \\
8(4.8 \%) \\
114(69.1 \%)\end{array}$} & $369(34.3 \%)$ \\
\hline & Medium & & & $126(11.7 \%)$ \\
\hline & Poor & & & $580(54 \%)$ \\
\hline \multirow[t]{2}{*}{ Residence } & \multirow{2}{*}{$\begin{array}{l}\text { Urban } \\
\text { Rural }\end{array}$} & \multirow{2}{*}{$\begin{array}{l}173(19 \%) \\
737(81.0 \%)\end{array}$} & \multirow{2}{*}{$\begin{array}{l}37(22.4 \%) \\
128(77.6 \%)\end{array}$} & $210(19.5 \%)$ \\
\hline & & & & $865(80.5 \%)$ \\
\hline
\end{tabular}




$\begin{array}{lllll}\text { Age -birth } & <20 & 524(57.6) & 93(56.4) & 617(57.4) \\ & 20-29 & \begin{array}{l}378(41.5) \\ 8(0.9)\end{array} & \begin{array}{l}68(41.2) \\ 4(2.4)\end{array} & 446(41.5) \\ & >=30 & & & 12(1.1) \\ \text { ANC } & <4 & 726(79.8) & 138(83.6) & 864(80.4) \\ & 4+ & 184(20.2) & 27(16.4) & 211(19.6) \\ \text { Num_chil } & 1-3 & 485(53.3) & 76(46.1) & 561(52.2) \\ & 4-6 & 283(31.1) & 53(32.1) & 336(31.3) \\ & 7+ & 142(15.6) & 36(21.8) & 178(16.6)\end{array}$

\section{Descriptive survival analysis}

The baby's survival time was determined as the time in month from birth until end of EBF or was censored (continued) at the end of the study. The median duration of EBF was 3 months, $25 \%$ of children terminated the EBF in the first 1 month and $75 \%$ of children terminated EBF in the first 4 months $(\mathrm{Q} 1=1$ month, $\mathrm{Q} 3=4$ months).

\subsection{Kaplan Meier Survival curve estimates}

A plot of Kaplan Meier survival probability corresponding to each duration of exclusive breastfeeding in month is shown on figure 1 below for two or more groups of women. Women in the medium and poor level category had higher and lower survival probability respectively than those in the rich level. Regarding the mode of birth, mothers who gave birth through their vaginal or Normal had higher survival probability than those who gave birth by means of caesarean. Similarly Employed mothers had longer survival probability than unemployed mothers.

The result of log-rank test (Table 2) showed that there was a significant difference between the different level of wealth index $\left(\chi^{2}=11.33\right.$, p-value=0.004), mode of delivery $\left(\chi^{2}=5.95\right.$, $\mathrm{p}$ value $=0.015)$, employment status $\left(\chi^{2}=10.64\right.$, $\mathrm{p}$-value $\left.=0.001\right)$, maternal education $\left(\chi^{2}=8.38\right.$, $\mathrm{p}$-value $=0.015)$, husband education $\left(\chi^{2}=12.62\right.$, $\mathrm{p}$-value $\left.=0.0018\right)$, and place of delivery $\left(\chi^{2}=\right.$ 4.39, p-value=0.036). On the other hand, there was no a significant difference between the different level of frequency of antenatal care, sex, residence, age at birth, and birth type.

Table 2. Log-rank and Wilcoxon test result showing the difference in survival functions among the groups of women 


\begin{tabular}{lllll}
\hline Predictor variable & $\begin{array}{l}\text { Log-rank } \\
\text { statistic }\end{array}$ & LP-value & $\begin{array}{l}\text { Wilcoxon } \\
\text { statistic }\end{array}$ & Wp-value \\
\hline ANC & 0.11 & 0.740 & 0.22 & 0.640 \\
Sex & 1.25 & 0.264 & 1.34 & 0.248 \\
Maternal education & 8.38 & 0.015 & 5.88 & 0.053 \\
Husband education & 12.62 & 0.0018 & 9.24 & 0.010 \\
residence & 1.76 & 0.184 & 1.10 & 0.295 \\
Age at birth & 3.38 & 0.185 & 0.18 & 0.913 \\
Place of delivery & 4.39 & 0.036 & 5.39 & 0.020 \\
Birth type & 2.29 & 0.131 & 1.17 & 0.280 \\
Wealth index & 11.33 & 0.004 & 14.40 & 0.001 \\
Mode of delivery & 5.95 & 0.015 & 3.43 & 0.064 \\
Employment status & 10.64 & 0.001 & 6.97 & 0.008 \\
Number of children ever born & 5.11 & 0.078 & 2.36 & 0.307 \\
\hline
\end{tabular}
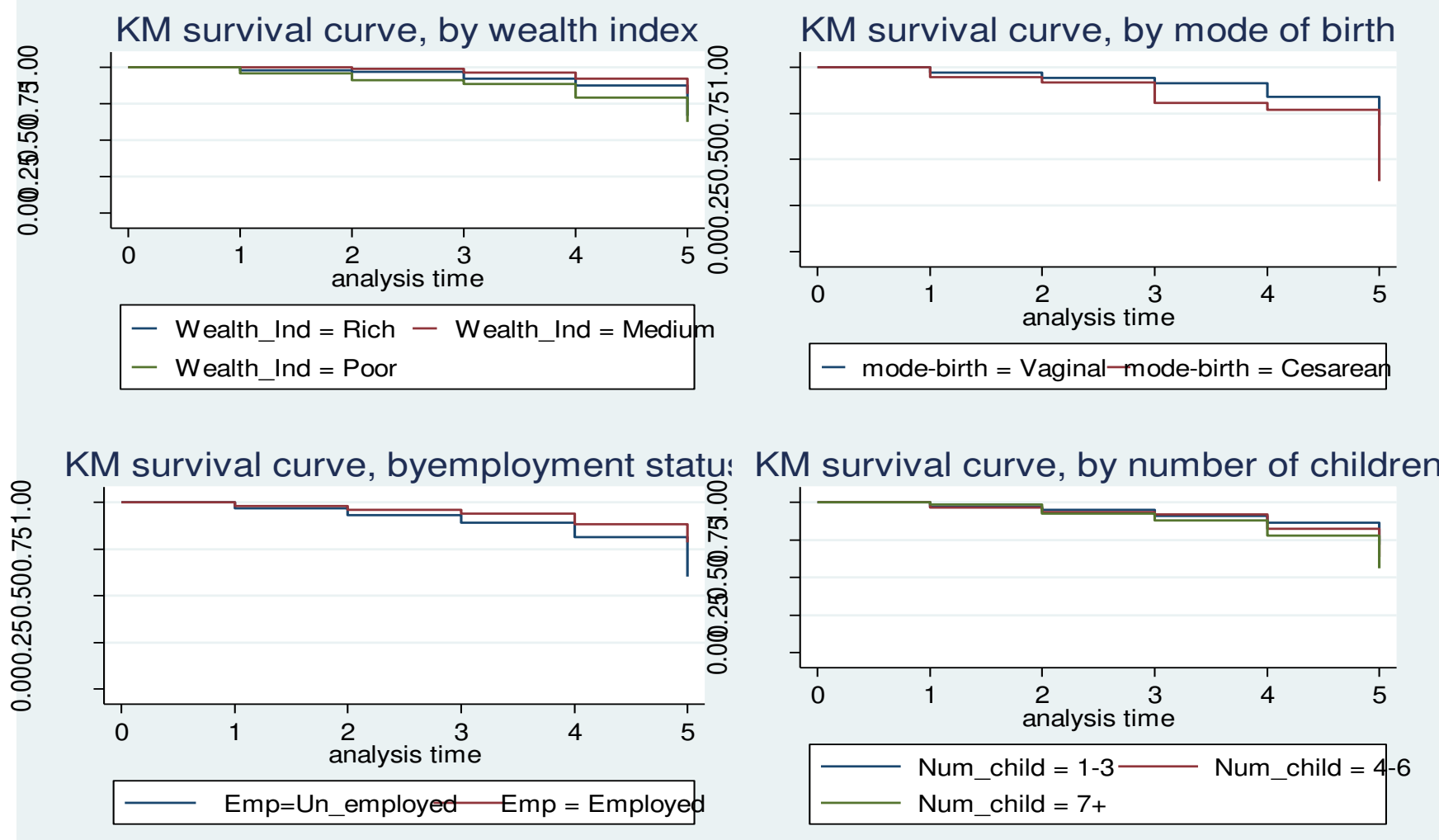

Figure 1: KM survival curves by wealth index, employment status, number of children ever born, and mode of delivery

\subsection{Cox Proportional Hazard Regression analysis}

Based on the contribution of each covariate to the maximized log partial likelihood of the model (-2LL), the significant change in -2LL is observed for place of delivery, wealth index, mode of 
delivery, number of children ever born, mother education and employment status comparing with that of null model $(-2 \mathrm{LL}=1688)$. Equivalently, by using Wald chi-square test, the variables above are significant at 25 percent level and candidate for the inclusion in the multivariate model (Table 3). On the other hand omitting the variables ANC, Sex, Birth interval, husband education, age at birth, residence, birth type, and age of mother does not bring a significant change on the value of -2LL. Once again, the number of children was significant at 5\% level at multivariate analysis. Therefore the main effects of the final model were wealth index, mode of delivery, employment status, and number of children ever born (Table 4\$5).

Table 3.Univariate Cox proportional Hazard Regression Analysis

\begin{tabular}{llllll}
\hline Covariates & -2LL & LR & LR-pvalue & Z-value & Z-pvalue \\
\hline ANC & 1688.02 & 0.10 & 0.7528 & 0.32 & 0.751 \\
Place-delivery & 1678.46 & 4.12 & 0.0424 & -1.99 & 0.047 \\
Sex & 1686.98 & 1.14 & 0.2863 & -1.06 & 0.287 \\
Birth interval & 1298.78 & 1.06 & 0.3022 & -1.03 & 0.303 \\
Wealth index & 1682.96 & 5.16 & 0.0231 & 2.23 & 0.026 \\
Mode- & 1683.79 & 4.33 & 0.0375 & 2.27 & 0.023 \\
delivery & & & & & \\
Num-children & 1683.65 & 4.47 & 0.0345 & 2.14 & 0.032 \\
Husband & 1597.01 & 1.34 & 0.2471 & -1.14 & 0.253 \\
education & & & & & \\
Age-1 & & & & \\
Mother & 1685.83 & 2.29 & 0.1303 & 1.52 & 0.128 \\
education & 1683.98 & 4.14 & 0.0420 & -1.97 & 0.049 \\
Residence & 1686.59 & 1.53 & 0.2155 & -1.26 & 0.206 \\
Birth type & 1686.55 & 1.57 & 0.2102 & 1.42 & 0.156 \\
Emp-status & 1677.76 & 10.37 & 0.0013 & -3.06 & 0.002 \\
$\begin{array}{l}\text { Age-mother } \\
\text { in group }\end{array}$ & 1687.68 & 0.44 & 0.5059 & 0.66 & 0.507 \\
\hline
\end{tabular}

-2loglikelihood for the null model=1688.12142

Table 4. Multivariate Cox proportional hazard regression analysis for EBF, 2016 EDHS data

\begin{tabular}{|l|l|l|l|l|l|l|}
\hline Covariates & Haz. Ratio & Std. Err. & $\mathrm{z}$ & $\mathrm{P}>\mathrm{z}$ & {$[$ 95\% Conf. } & Interval] \\
\hline pla_delivery & .8263781 & .2013846 & -0.78 & 0.434 & .5125601 & 1.332333 \\
\hline Wealth_Ind & 1.293562 & .1608867 & 2.07 & 0.038 & 1.013722 & 1.650651 \\
\hline Birth_method & 3.309976 & 1.151116 & 3.44 & 0.001 & 1.674176 & 6.54408 \\
\hline Num_children & 1.202646 & .1424024 & 1.56 & 0.119 & .9535625 & 1.516794 \\
\hline Husband_education & 1.084809 & .1672199 & 0.53 & 0.597 & .8019427 & 1.46745 \\
\hline
\end{tabular}




\begin{tabular}{|l|l|l|l|l|l|l|}
\hline Moth_Educa & .8294718 & .1552497 & -1.00 & 0.318 & .5747577 & 1.197067 \\
\hline Occ_wom & 1.786384 & .6773961 & 1.53 & 0.126 & .8495705 & 3.756212 \\
\hline Emp_mother & .2586527 & .1695989 & -2.06 & 0.039 & .0715456 & .9350846 \\
\hline
\end{tabular}

Table 5. Multivariate Cox proportional hazard regression result for the main effects, 2016 EBF, EDHS data

\begin{tabular}{|l|l|l|l|l|l|l|}
\hline Covariates & Haz. & Ratio & $\begin{array}{l}\text { Std. } \\
\text { Err. }\end{array}$ & \multicolumn{2}{|l|}{ Z p-value } & \multicolumn{2}{|l|}{} \\
\hline Wealth_Ind & 1.262262 & .1298539 & 2.26 & 0.024 & 1.03177 & 1.544244 \\
\hline Birth_method & 2.727933 & .8412134 & 3.25 & 0.001 & 1.490557 & 4.99251 \\
\hline Emp_mother & .5529215 & .1118176 & -2.93 & 0.003 & .3719842 & .8218686 \\
\hline Num_children & 1.264253 & .1361631 & 2.18 & 0.029 & 1.023664 & 1.561387 \\
\hline
\end{tabular}

\subsection{Model Adequacy}

$\log -\log$ Plot and Schoenfeld residual are used to check ph assumption. $\log (-\log (S(t)))$ Plot showed that even though wealth index, mode of birth, employment of status had satisfied assumptions relatively the parallel is not enough (figure2). The result of Global test and individual proportional hazards test shown below (Table 6) indicated that except for wealth index ( $\mathrm{p}$-value $=0.0473$ ), the test do not suggests the violation of ph assumption for birth method and employment status. In addition from Cox-Snell residual analysis we observed that the Cox model does not fit the data well; as it departed from $45^{\circ}$ reference line which suggests the need of alternative accelerated failure time (figure 4).

Table 6. Global and individual proportion hazard assumption test result

\begin{tabular}{|l|l|l|l|l|}
\hline & Rho $(\rho)$ & Chi-square & Df & p-value \\
\hline Wealth index & 0.16950 & 3.94 & 1 & 0.0473 \\
\hline Birth method & -0.02816 & 0.10 & 1 & 0.7517 \\
\hline $\begin{array}{l}\text { Employment } \\
\text { status }\end{array}$ & -0.04612 & 0.29 & 1 & 0.5882 \\
\hline Global test & & 4.17 & 3 & 0.2438 \\
\hline
\end{tabular}

\subsection{Performance of CPH regression and AFT models and effect of significant factors}

Among the compared models Weibull model $(\mathrm{AIC}=675.255)$ was found to be better to fit the effect of covariates on the duration of exclusive breastfeeding (Table7). Accordingly, the estimated coefficient of poor level wealth index is -0.1745 , which suggests poor level mothers decrease the duration of EBF approximately by 16 percent 
$(\exp (-0.1745)=0.84,95 \% C I:(0.72,0.98)$ compared to those in the rich level. The estimated coefficient of employed mothers is 0.233 , which suggests the employed mothers increase the duration of EBF approximately by 26 percent $((\exp (0.233)=1.262), 95 \% C I:(1.08,1.48))$ compared to unemployed mothers. Moreover, the mothers who gave birth by cesarean shorten the duration of EBF approximately by 29 percent $(\exp (-0.3421)=0.71,95 \% C I:(0.56,0.90))$.

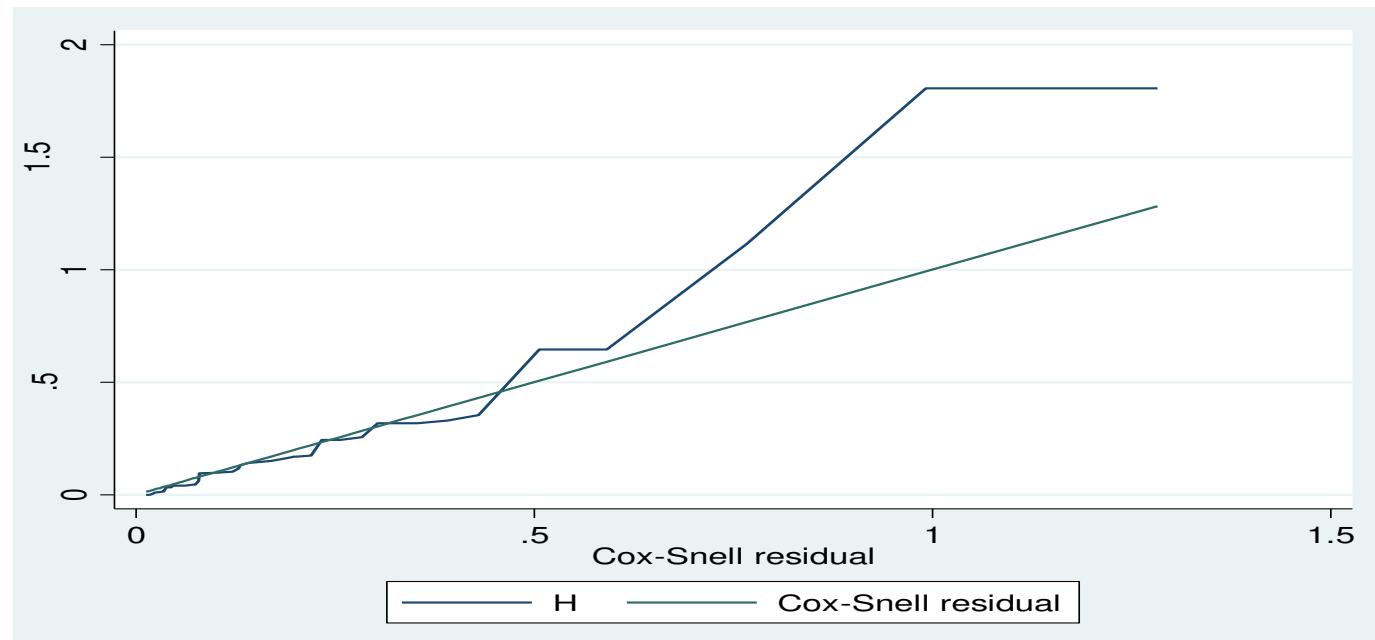

Figure 4. Cox Snell residual plot for the fitted Cox proportional hazard regression model Table 7. Model comparison b/n CPH and AFT model result

\begin{tabular}{|l|l|l|l|l|}
\hline Model & AIC & BIC & Log-likelihood & LR \\
\hline CPH & 1669.851 & 1689.048 & -830.92571 & 26.27 \\
\hline Weibull & 675.2551 & 704.0494 & -331.62754 & 26.72 \\
\hline Exponential & 802.7637 & 826.7589 & -396.38183 & 26.77 \\
\hline Log-Normal & 703.919 & 732.7134 & -345.95951 & 26.59 \\
\hline Log-logistic & 687.16 & 715.9544 & -337.58002 & 25.06 \\
\hline
\end{tabular}

Table 8. The result of Weibull Accelerated failure time Model 


\begin{tabular}{|c|c|c|c|c|c|c|}
\hline Covariate & Coef. & Std.Err & Zvalue & $\mathrm{P}|\mathrm{Z}|$ value & \multicolumn{2}{|c|}{ 95\% Conf.Int } \\
\hline \multicolumn{7}{|l|}{ Wealth_Ind } \\
\hline Medium & .2233288 & .1504696 & 1.48 & 0.138 & -.0715861 & .5182438 \\
\hline Poor & -.1744783 & .0777315 & -2.24 & 0.025 & -.3268292 & -.0221275 \\
\hline \multicolumn{7}{|l|}{ Emp_mother } \\
\hline Employed & .2332747 & .0795491 & 2.93 & 0.003 & .0773613 & .3891882 \\
\hline \multicolumn{7}{|l|}{ Birth_method } \\
\hline Cesarean & -.3420697 & .1218089 & -2.81 & 0.005 & -.5808108 & -.1033287 \\
\hline _cons & 2.022595 & .081769 & 24.74 & 0.000 & 1.86233 & 2.182859 \\
\hline$/ \operatorname{lnp}$ & .9536262 & .069747 & 13.67 & 0.000 & .8169245 & 1.090328 \\
\hline $\mathrm{p}$ & 2.595103 & .1810007 & & & 2.263528 & 2.975249 \\
\hline $1 / \mathrm{p}$ & .3853412 & .0268764 & & & .3361063 & .4417883 \\
\hline
\end{tabular}

\section{DISCUSSION}

This study attempted to identify the factors that affect the duration of exclusive breastfeeding by comparing the performance of CPH regression and AFT model. No studies have been conducted to compare the performance of $\mathrm{CPH}$ regression and AFT model for EBF data in Ethiopia. In this study prevalence of EBF was higher (84.7\%). This is higher as compared to the prevalence of EBF in different parts of Ethiopia, which ranges from $20.9 \%$ in Gondar to $81.1 \%$ in Dubti town of Afar region $[[1,2,3,6,7,10-18,22,24,25,27]$. The median duration of EBF in this study was 3 months which is shorter than that of a study found by Chudasamaa etal, Agampodi etal, and Giashuddin etal, 6,4, and 3.67 months respectively[30-33]. In contrast, it was higher than the median duration of EBF in Indonesia, Conko kinshasha and it was consistent with study done in Brazil (3 months) and Gobba district of Ethiopia [23, 29, 36].

The present study found that the mode of delivery is a significant predictor of duration of EBF. The estimated coefficient of mothers who gave birth by cesarean is $-0.3421: \mathrm{TR}=$ $\exp (-0.3421)=0.71$ which suggests the mothers who gave birth by cesarean decrease the duration of EBF approximately by 29 percent compared to mothers who gave birth vaginally. Similar findings obtained by $[1,4,22,24]$ revealed that mothers who gave birth vaginally were more likely to practice EBF than those who gave birth by cesarean section. In contrast, a study by [28] found that children of mothers who experienced cesarean section had $29 \%$ lower risk of finishing $\mathrm{EBF}$ before six months $(\mathrm{HR}=0.71$, 95\% CI:(0.55,0.91)) compared with children whose mothers had vaginal delivery. 
This study found that the employed mothers increase the duration of EBF approximately by 26 percent $((\mathrm{TR}=\exp (0.233)=1.262), 95 \% C I:(1.08,1.48))$ compared to unemployed mothers. This might be unemployed mothers early discontinued EBF to search a job for their daily food. This study agreed with the study done in Goba, and Somali regional state of Ethiopia [23, 37]. In contrast, the study found by Hunegnaw et al., indicated that government employee mothers decreased the time of breastfeeding by 2.8 times $(\mathrm{AHR}=2.8,95 \%$ : 1.80,4.40) compared to housewives and study in Debre berhan district found that employed mothers were 0.36 times less likely to practice $\mathrm{EBF}(\mathrm{AOR}=0.36,95 \% \mathrm{CI}: 0.18,0.73)$ than housewives [13,19].

A study by Tika Dwi Tama and Erni Astatuk (2018), Adugna etal.(2017), and Seid etal (2013) found that Place of delivery was significantly associated with duration of exclusive breastfeeding. In these studies, Mothers who gave birth in health facilities have longer duration in breastfeeding practice compared as mothers who gave birth in other places. In contrast, the present study showed that place of delivery and mother's education level had not significant effect on the duration of exclusive breastfeeding $[8,22,36]$.

According to our study, mothers whose wealth index is in poor level decrease the duration of EBF approximately by 16 percent $(\mathrm{TR}=\exp (-0.1745)=0.84,95 \% C I:(0.72,0.98)$ compared to those in the rich level. This is similar with that found by Chekol et al [16].

Conclusion: being unemployed and gave birth by cesarean shortens the duration of EBF. On the other hand, poor mothers discontinued EBF early than rich mothers. Therefore special emphasis should be given for unemployed and poor mothers and also for those gave birth by cesarean. On the other hand, Weibull accelerated failure time model was better than $\mathrm{CPH}$ model to determine the associated factors of EBF duration. Therefore, the study recommends this model as alternative of $\mathrm{CPH}$ model. 


\section{References}

1. Yeneabat T, Belachew T, Haile M. Determinants of cessation of exclusive breastfeeding in Ankesha Guagusa Woreda, Awi Zone, Northwest Ethiopia: a cross-sectional study. BMC pregnancy and childbirth. 2014 Dec;14(1):1-2.

2. Seifu W, Assefa G, Egata G. Prevalence of exclusive breast feeding and its predictors among infants aged six months in Jimma Town, Southwest Ethiopia, 2013. J Pediatr Neonatal Care. 2014;1(3):00017.

3. Kelaye T. Assessment of Prevalence of Exclusive Breast Feeding Practice and Associated Factors among Under Six-Month-Old Children Selected Woreda South Nation Nationality of People Regional State, Ethiopia, 2016. J Nutr Health Food Sci [Internet]. 2017;27:1-7..

4. Kasahun AW, Wako WG, Gebere MW, Neima GH. Predictors of exclusive breastfeeding duration among 6-12 month aged children in gurage zone, South Ethiopia: a survival analysis. International breastfeeding journal. 2016 Dec;12(1):1-9.

5. NA T, AV W. Survival Analysis of Duration of Exclusive Breast Feeding Using Life Table and Hazard Function. Journal of Krishna Institute of Medical Sciences (JKIMSU). 2015 Jan 1;4(1).

6. Ten facts about breastfeeding, World Health Organization,2012.

7. Alebel A, Tesma C, Temesgen B, Ferede A, Kibret GD. Exclusive breastfeeding practice in Ethiopia and its association with antenatal care and institutional delivery: a systematic review and meta-analysis. International breastfeeding journal. 2018 Dec;13(1):1-2.

8. Adugna B, Tadele H, Reta F, Berhan Y. Determinants of exclusive breastfeeding in infants less than six months of age in Hawassa, an urban setting, Ethiopia. International breastfeeding journal. 2017 Dec; 12(1):1-8.

9. Getahun EA, Hayelom DH, Kassie GG. Exclusive breast feeding practice and associated factors in kemba woreda, southern Ethiopia, a community based cross-sectional study. International Journal of Science, Technology and Society. 2017 Jun 1; 5(4):55.

10. Ahmed KY, Page A, Arora A, Ogbo FA. Trends and determinants of early initiation of breastfeeding and exclusive breastfeeding in Ethiopia from 2000 to 2016. International breastfeeding journal. 2019 Dec;14(1):1-4. 
11. Alemayehu T, Haidar J, Habte D. Determinants of exclusive breastfeeding practices in Ethiopia. Ethiopian Journal of Health Development. 2009;23(1).

12. Earsido A, Abebe W, Dereje N. Prevalence and determinants of exclusive breastfeeding practices among infants in Hossana town, southern Ethiopia: a community based crosssectional study. EC Gynaecology. 2017;4(2017):69-79.

13. Asfaw MM, Argaw MD, Kefene ZK. Factors associated with exclusive breastfeeding practices in Debre Berhan District, Central Ethiopia: a cross sectional community based study. International breastfeeding journal. 2015 Dec;10(1):1-9.

14. Behzadifar M, Saki M, Behzadifar M, Mardani M, Yari F, Ebrahimzadeh F, Mehr HM, Bastami SA, Bragazzi NL. Prevalence of exclusive breastfeeding practice in the first six months of life and its determinants in Iran: a systematic review and meta-analysis. BMC pediatrics. 2019 Dec;19(1):1-0.

15. Beyene AM, Liben ML, Arora A. Factors associated with the early termination of exclusive breastfeeding among mother-infant dyads in Samara-Logia, Northeastern Ethiopia. BMC pediatrics. 2019 Dec;19(1):1-9.

16. Chekol DA, Biks GA, Gelaw YA, Melsew YA. Exclusive breastfeeding and mothers' employment status in Gondar town, Northwest Ethiopia: a comparative cross-sectional study. International breastfeeding journal. 2017 Dec; 12(1):1-9.

17. Elyas L, Mekasha A, Admasie A, Assefa E. Exclusive breastfeeding practice and associated factors among mothers attending private pediatric and child clinics, Addis Ababa, Ethiopia: a cross-sectional study. International journal of pediatrics. 2017 Dec 3; 2017.

18. Bazie E, Birara A. Exclusive breast feeding prevalence and associated factors an institutional based cross sectional study in Bahir dar Northwest Ethiopia. International Journal of Homeopathy \& Natural Medicines. 2019 Jul 15;5(1):42.

19. Hunegnaw MT, Gelaye KA, Ali BM. Factors associated with the time to cessation of breastfeeding among mothers who have index children aged two to three years in Debre Markos, northwest Ethiopia: a retrospective follow up study. BMC pediatrics. 2018 Dec; $18(1): 1-8$.

20. Liben ML, Gemechu YB, Adugnew M, Asrade A, Adamie B, Gebremedin E, Melak Y. Factors associated with exclusive breastfeeding practices among mothers in dubti town, 
afar regional state, Northeast Ethiopia: a community based cross-sectional study. International breastfeeding journal. 2016 Dec;11(1):1-6.

21. Taddele M, Abebe L, Fentahun N. Exclusive breastfeeding and maternal employment in Ethiopia: a comparative cross-sectional study. Int J Nutr Food Sci. 2014 Oct 22;3(6):497503.

22. Seid AM, Yesuf ME, Koye DN. Prevalence of Exclusive Breastfeeding Practices and associated factors among mothers in Bahir Dar city, Northwest Ethiopia: a community based cross-sectional study. International breastfeeding journal. 2013 Dec;8(1):1-8.

23. Setegn T, Belachew T, Gerbaba M, Deribe K, Deribew A, Biadgilign S. Factors associated with exclusive breastfeeding practices among mothers in Goba district, south east Ethiopia: a cross-sectional study. International breastfeeding journal. 2012 Dec;7(1):1-8.

24. Shifraw T, Worku A, Berhane Y. Factors associated exclusive breastfeeding practices of urban women in Addis Ababa public health centers, Ethiopia: a cross sectional study. International breastfeeding journal. 2015 Dec;10(1):1-6.

25. Woldie TG, Kassa AW, Edris M. Assessment of exclusive breast feeding practice and associated factors in Mecha District, North West Ethiopia. Sci J Public Health. 2014 Jul 22;2(4):330-6.

26. Tewabe T, Mandesh A, Gualu T, Alem G, Mekuria G, Zeleke H. Exclusive breastfeeding practice and associated factors among mothers in Motta town, East Gojjam zone, Amhara Regional State, Ethiopia, 2015: a cross-sectional study. International breastfeeding journal. 2016 Dec;12(1):1-7.

27. Ayalew T. Exclusive breastfeeding practice and associated factors among first-time mothers in Bahir Dar city, north West Ethiopia, removed: a community based cross sectional study. Heliyon. 2020 Sep 1;6(9):e04732.

28. do Carmo Lessa A, Freitas RF, Fonseca LB, de Oliveira Assis AM. Duration and Determinants of Breastfeeding: A Cohort Study.

29. Babakazo P, Donnen P, Akilimali P, Ali NM, Okitolonda E. Predictors of discontinuing exclusive breastfeeding before six months among mothers in Kinshasa: a prospective study. International Breastfeeding Journal. 2015 Dec;10(1):1-9. 
30. Xu F, Binns C, Zheng S, Wang Y, Zhao Y, Lee A. Determinants of exclusive breastfeeding duration in Xinjiang, PR China. Asia Pacific journal of clinical nutrition. 2007 Jun $1 ; 16(2)$.

31. Chudasama RK, Patel PC, Kavishwar AB. Factors associated with duration of exclusive breastfeeding. The Internet Journal of Pediatrics and Neonatology. 2008;9(1):1-6.

32. Agampodi SB, Fernando S, Dharmaratne SD, Agampodi TC. Duration of exclusive breastfeeding; validity of retrospective assessment at nine months of age. BMC pediatrics. $2011 \mathrm{Dec} ; 11(1): 1-5$.

33. Giashuddin MS, Kabir M. Duration of breast-feeding in Bangladesh. Indian Journal of Medical Research. 2004 Jun 1;119: 267-72.

34. Feldens CA, Vitolo MR, Rauber F, Cruz LN, Hilgert JB. Risk factors for discontinuing breastfeeding in southern Brazil: a survival analysis. Maternal and child health journal. 2012 Aug;16(6):1257-65.

35. Vieira TO, Vieira GO, de Oliveira NF, Mendes CM, Giugliani ER, Silva LR. Duration of exclusive breastfeeding in a Brazilian population: new determinants in a cohort study. BMC pregnancy and childbirth. 2014 Dec; 14(1):1-9.

36. Tama TD, Astutik E. Exclusive Breastfeeding Survival And Factors Related to Early Breastfeeding Cessation in Indonesia. In2nd International Conference on Sports Sciences and Health 2018 (2nd ICSSH 2018) 2019 Feb (pp. 183-186). Atlantis Press.

37. Tadesse F, Alemayehu Y, Shine S, Asresahegn H, Tadesse T. Exclusive breastfeeding and maternal employment among mothers of infants from three to five months old in the Fafan zone, Somali regional state of Ethiopia: a comparative cross-sectional study. BMC Public Health. 2019 Dec;19(1):1-9.

\section{Abbreviations}

EBF: Exclusive breastfeeding; EDHS: Ethiopian Demographic and Health Survey; AFT: accelerated failure time; WHO: World Health Organization; CPH: Cox proportional Hazard; TR: time ratio

\section{Acknowledgement}

We would like to thank CSA of Ethiopia for the allowing as for the availability of data. 


\section{Authors' contribution}

BE wrote the proposal, organized, coded, entered, and analyzed, interpreted the data, and wrote the conclusion and manuscript in consultation with the TB .TB collected the data from CSA, read, edited, and gave critical comments on data analysis and manuscript. Finally, both authors read and approved the final manuscript.

\section{Funding}

No funding obtained for this study

\section{Consent for publication}

Not applicable

\section{Competing interests}

The authors declare that they have no competing interest

\section{Availability of data and materials}

The data set was demanded and retrieved from CSA website after formal online registration and submission of the project title and description. The data can be accessed through http://www.statsethiopia .gov.et/. 